\title{
The Role of Single-Nucleotide Variants of NOS1, NOS2, and NOS3 Genes in the Comorbidity of Arterial Hypertension and Tension-Type Headache
}

\author{
Natalia A. Shnayder 1,2,*, Marina M. Petrova ${ }^{1}$, Polina V. Moskaleva ${ }^{1, *}$, Pavel A. Shesternya ${ }^{1}$, \\ Elena A. Pozhilenkova ${ }^{1}$ and Regina F. Nasyrova ${ }^{2, *}$ \\ 1 V. F. Voino-Yasenetsky Krasnoyarsk State Medical University, 660022 Krasnoyarsk, Russia; \\ stk99@yandex.ru (M.M.P.); sci-prorector@krasgmu.ru (P.A.S.); elena.a.pozhilenkova@gmail.com (E.A.P.) \\ 2 V.M. Bekhterev National Research Medical Center for Psychiatry and Neurology, \\ 199034 Saint-Petersburg, Russia \\ * Correspondence: naschnaider@yandex.ru (N.A.S.); polina-moscaleva@yandex.ru (P.V.M.); \\ nreginaf77@gmail.com (R.F.N.); Tel.: +7-(913)-535-47-77 (N.A.S.); +7-(983)-147-03-61 (P.V.M.); \\ +7-(981)-109-71-34 (R.F.N.)
}

Citation: Shnayder, N.A.; Petrova, M.M.; Moskaleva, P.V.; Shesternya, P.A.; Pozhilenkova, E.A.; Nasyrova, R.F. The Role of SingleNucleotide Variants of NOS1, NOS2, and NOS3 Genes in the Comorbidity of Arterial Hypertension and TensionType Headache. Molecules 2021, 26, 1556. https://doi.org/10.3390/ molecules26061556

Academic Editors: Cristina Maccallini and Rosa Amoroso

Received: 16 February 2021

Accepted: 9 March 2021

Published: 12 March 2021

Publisher's Note: MDPI stays neutral with regard to jurisdictional claims in published maps and institutional affiliations.

Copyright: (C) 2021 by the authors Licensee MDPI, Basel, Switzerland. This article is an open access article distributed under the terms and conditions of the Creative Commons Attribution (CC BY) license (https:// creativecommons.org/licenses/by/ $4.0 /)$.
Abstract: Patients with tension-type headache (TTH) have an increased risk of developing arterial hypertension $(\mathrm{AH})$, while hypertensive subjects do seem to have an increased risk of TTH. We searched for full-text English publications in databases using keywords and combined word searches over the past 15 years. In addition, earlier publications of historical interest were included in the review. In our review, we summed up the single nucleotide variants (SNVs) of Nitric Oxide Synthases (NOSs) genes involved in the development of essential AH and TTH. The results of studies we discussed in this review are contradictory. This might be due to different designs of the studies, small sample sizes in some of them, as well as different social and geographical characteristics. However, the contribution of genetic and environmental factors remains understudied. This makes the issue interesting for researchers, as understanding these mechanisms can contribute to a search for new approaches to pathogenetic and disease-modifying treatment of the AH and TTH phenotype. New drugs against AH and TTH can be based on inhibition of nitric oxide (NO) production, blockade of steps in the NO-cGMP pathway, or NO scavenging. Indeed, selective neuronal NOS (n-NOS) and inducible NOS (i-NOS) inhibitors are already in early clinical development.

Keywords: nitric oxide; nitric oxide synthase; single nucleotide variants; polymorphisms; genes; NOS1; NOS2; NOS3; arterial hypertension; tension-type headache

\section{Introduction}

Arterial hypertension $(\mathrm{AH})$ is a prevalent condition worldwide and is the key risk factor for non-fatal and fatal cardiovascular complications [1]. Tension-type headache (TTH) is the most common type of primary headache and is considered a common everyday headache [2]. Many studies support the hypothesis that TTH patients have an increased risk of developing $\mathrm{AH}$, while hypertensive subjects do seem to have an increased risk of TTH. The relationship between AH and TTH is potentially of great pathophysiological and clinical interest, but it is poorly understood [3]. This allows us to hypothesize the presence of the AH and TTH phenotype.

The pathophysiological patterns are significantly different in the setting of chronic pain, in which the adaptive relationship between blood pressure and pain sensitivity is reversed. The connection between acute or chronic pain and cardiovascular changes is supported observationally [4], but some of this indirect evidence is confirmed by experimental animal models and human studies. AH and TTH may share common mechanisms like endothelial dysfunction, deficiency of autonomic cardiovascular regulation, and renin angiotensin system involvement. 
Nitric oxide (NO) is an important autocrine and paracrine signaling molecule that plays a crucial role in cardiovascular physiology and pathology regulation. NO is an important molecule involved in regulation of cerebral and extra cerebral cranial blood flow and arterial diameters [5]. Reduced bioavailability of NO in the endothelium is an important precursor for impaired vasodilation and $\mathrm{AH}$. Furthermore, $\mathrm{NO}$ is involved in nociceptive processing. A NO-induced biphasic response with an immediate and a delayed headache is common to chronic TTH in humans [6].

NO-synthases (NOSs) are expressed in three isoforms, including neuronal NOS (nNOS, NOS1), inducible NOS (iNOS, NOS2), and endothelial NOS (eNOS, NOS3) [7]. All NOS isoforms can catalyze the conversion of l-arginine to L-citrulline and NO (Figure 1). The active NOSs form a homodimer and convert the amino acid L-arginine to L-citrulline and NO. The NOS monomer contains a C-terminal reductase domain and a $\mathrm{N}$-terminal oxygenase domain, which are linked by the calmodulin $(\mathrm{CaM})$ binding region. The $\mathrm{N}$ terminal oxidase domain contains the heme, tetrahydrobiopterin cofactors (BH4), and the binding site for the substrate arginine. The oxidase domain is the active site of $\mathrm{NO}$ synthesis. Production of $\mathrm{NO}$ requires $\mathrm{O}_{2}$ as an electron acceptor. NO diffuses freely across the plasma membrane. Therefore, $\mathrm{NO}$ can be transported to effector proteins in the adjacent cells and exert its effects (e.g., endothelial NO targets soluble guanylate cyclase (sGC) in smooth muscle to accomplish vasodilation) [8].

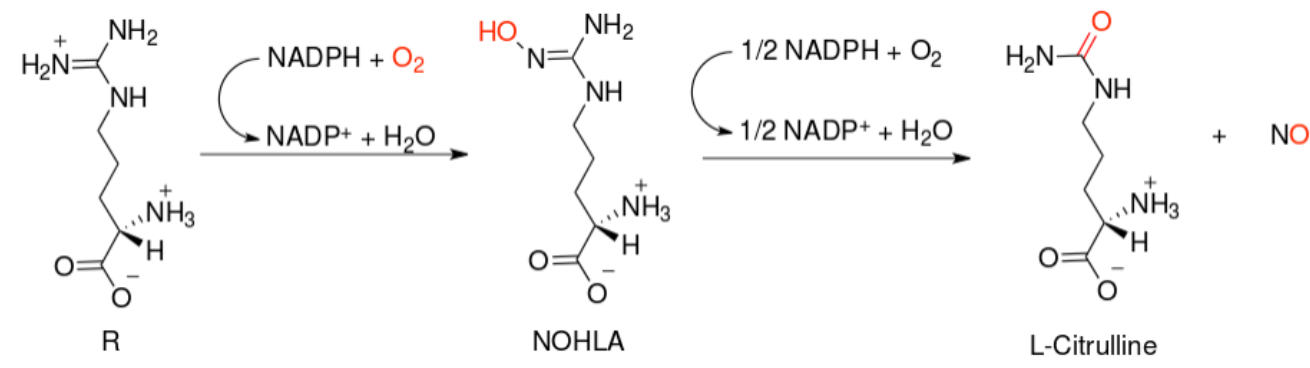

Figure 1. Scheme of nitric oxide (NO) formation from L-arginine in humans.

NOS1 and NOS3 are commonly associated with low levels of NO production, which mediates intracellular signaling processes (NOS1) and vascular homeostasis (NOS3). In addition to NO production, eNOS can function in an uncoupled manner and produce ROS when the available stores of $\mathrm{BH} 4$ are removed or oxidized, 1-arginine is depleted, or the eNOS inhibitor asymmetric dimethyl-l-arginine is overexpressed $[9,10]$. nNOS and eNOS are most commonly found in non-immunological cells (e.g., neurons, muscle, endothelium). As their NO output is relatively low, these isoforms are considered less immunologically important than their inducible counterpart, iNOS [7].

$\mathrm{NO}$ and NOSs play an important role in the pathogenesis and treatment of both $\mathrm{AH}$ and TTH. In particular, NOSs affect the sensitivity of the brain to stress and changes in systemic and local hemodynamics [11]. In addition, a NO-synthesis change in endothelial cells of peripheral and cerebral vessels is one of the identified causes of NO-dependent vasospasm (impaired NO-dependent vasodilation) in patients with AH [12] and TTH [13], as well as chronic pain syndrome $[13,14]$ and changes in the response to antihypertensive drugs [15] and analgesics [16,17]. However, the functional activity of enzymes of the NOS family depends on the carriage of wild, highly functional, low functional, and nonfunctional single nucleotide variants (SNVs) of NOS1, NOS2, and NOS3 genes encoding the enzyme isoforms.

The aim of the review is to study the role of SNVs of the NOS1, NOS2, and NOS3 genes in the comorbidity of arterial hypertension and tension-type headache.

\section{Results}

The NOS family proteins are encoded by the genes NOS1 (also known as: N-NOS, NCNOS, $n N O S$, bNOS, IHPS1), NOS2 (also known as: I-NOS, NOS2A, iNOS, HEP-NOS), and 
NOS3 (also known as: eNOS, ECNOS) [18]. SNVs of genes encoding NOSs can affect their expression level and/or activity in organs and tissues. Experimental evidence suggests that nNOS (NOS1), iNOS (NOS2), and eNOS (NOS3) have important effects on cardiovascular function and pain, but their cumulative effect on the AH and TTH phenotype in humans is unknown. Therefore, the phenotype requires a better treatment. Association studies related to the role of SNVs of NOS1, NOS2, and NOS3 genes in the development of AH and TTH phenotype are of scientific and clinical interest.

\subsection{NOS1 Gene}

The NOS1 gene is localized on chromosome 12q24.22 (exon count: 33) [18]. There are biased expressions of NOS1 in brain (RPKM 1.1), kidney (RPKM 1.0), and 11 other tissues [19]. This protein is ubiquitously expressed, especially in skeletal muscle. Multiple transcript variants that differ in the $5^{\prime}$ UTR have been described for the NOS1 gene, but the full-length nature of these transcripts is not known. Additionally, alternatively spliced transcript variants encoding different isoforms (some testis-specific) have been found for this gene [18].

Levinsson A. et al. (2014) found that the carriage of the T allele rs 3782218 of the NOS1 gene reduces the risk of developing AH (odds ratio $(\mathrm{OR})=0.81,95 \%$ confidential interval $(\mathrm{CI})=0.67-0.97, p=0.02)$, and the carriage of the A allele rs7314935, on the contrary, increases this risk $(\mathrm{OR}=2.15, \mathrm{CI}=1.06-4.37, p=0.03)$ [20]. The role SNVs in headache development (Alaşehirli B. et al. (2013) [21] and García-Martín E. et al. (2015) [22]) was studied, but no associations were found in patients with migraine.

\subsection{NOS2 Gene}

The NOS2 gene is localized on chromosome 17q11.2 (exon count: 27) [18]. There are biased expressions of NOS2 in the small intestine (RPKM 10.3), appendix (RPKM 7.9), and five other tissues [19]. The inducible NOS (iNOS) function produced by the NOS2 gene is activated to combat environmental factors.

Fu L. et al. (2009) investigated the association between SNV rs2779249 (-1026C/A) of the NOS2 promoter and susceptibility to AH in Chinese Han [23]. Significant differences were found in the genotype and allele frequencies of the NOS2 rs2779249 $(p<0.05)$; the genotype $\mathrm{CC}$ was associated with $\mathrm{AH}$ after adjusting for environmental risk factors through nonconditional logistic regression analysis (adjusted $\mathrm{OR}=2.90 ; \mathrm{CI}=2.14-3.93$ ). Transmission disequilibrium test analysis demonstrated that allele $\mathrm{C}$ was preferentially transmitted within pedigree (combined Z score 2.257, $p<0.05$ ). The NOS2 rs2779249 was identified by a construct reporter assay as a functional variant, and the transcriptional activity of the promoter with allele $C$ was 4.73 -fold lower than that with allele A. Furthermore, a electrophoresis mobility shift assay showed that rs2779249 changed the $Y$ in Yang 1 (YY1)-binding pattern in vitro, whereas chromatin immunoprecipitation showed that transcription factor YY1 was bound to the variant 1026C (rs2779249) in vivo. Lipopolysaccharide, an inflammatory stimulating factor, could induce YY1 to augment DNA-binding affinity; it could also be involved in the inhibited transcriptional activity of the NOS2 promoter with allele C. The authors thus conclude that NOS2 rs2779249 with a change in YY1-binding affinity is associated with AH due to the effect of inflammatory-stimulating factors [23].

The risk of essential AH was assessed in carriers of the NOS2 gene variants rs1800482 $(-954 \mathrm{G}>\mathrm{C})$ and rs3730017 (C>T). In subjects carrying allele C (rs1800482), the risk of essential AH developing was 1.7 times higher ( $\mathrm{OR}=1.712,95 \% \mathrm{CI} 1.07-2.74)$, while the presence of the $\mathrm{T}$ allele (rs3730017) had a protective effect $(\mathrm{OR}=0.304,95 \% \mathrm{CI} 0.192-0.482)$. In patients with essential $\mathrm{AH}$, the presence of the $\mathrm{C}$ allele (rs1800482) was associated with a higher content of NO metabolites in the blood plasma [24]. Furthermore, Topchieva L.V. et al. (2019) determined the influence of the $\mathrm{C}$ allele on the VCAM1 and ICAM1 gene expression in patients with essential $\mathrm{AH}$. It was hypothesized that this polymorphic site 
in the NOS2 gene can be involved in the development of endothelial dysfunction and essential AH through modulation of the NO level in inflammation [24].

Less is known on whether the two SNVs in the NOS2 gene (rs2779249 $(1026 \mathrm{C}>\mathrm{A}))$, rs2297518 (2087G>A)) affect susceptibility to AH. Nikkari S.T. et al. (2015), in the Tampere adult population cardiovascular risk study (TAMRISK), established the association between these SNVs and AH diagnosed in a Finnish cohort [25]. Data analysis was done by logit regression. At the age of 50, the SNP rs 2779249 is associated significantly with AH ( $p=0.009)$; specifically, subjects carrying the A-allele had higher risk of AH compared to those carrying the $C \mathrm{C}$ genotype $(\mathrm{OR}=1.47 ; \mathrm{CI}=1.08-2.01 ; p=0.015)$. In addition, a 15 -year follow-up period $(35,40$, and 45 years) of the same individuals showed that carriers of the A-allele had AH more often in all of the studied age groups. The highest risk of developing $\mathrm{AH}$ was observed among 35-year-old subjects $(\mathrm{OR}=3.83 ; \mathrm{CI}=1.20-12.27 ; p$ $=0.024)$. Those carrying variant $\mathrm{A}$ also had significantly higher readings of both systolic $(p=0.047)$ and diastolic $(p=0.048)$ blood pressure during the follow-up. No significant associations between rs2297518 variant alone and AH were found. However, haplotype analysis of rs2779249 and rs2297518 revealed that individuals having haplotype H3, which combines both A alleles (CA-GA, 19.7\% of individuals), were more commonly found in the hypertensive group than in the normotensive group $(\mathrm{OR}=2.01 ; \mathrm{CI}=1.29-3.12$; $p=0.002)$. In conclusion, there was a significant association between the NOS2 genetic variant (rs2779249) and AH in the genetically homogenous Finnish population. Those who carried the rare A-allele of the gene already had higher risk for $\mathrm{AH}$ at the age of 35 years [25].

Zhai Z. et al. (2018) studied the association between SNVs rs2779249 and rs2297518 of the NOS2 gene and AH in a Han Chinese cohort [26]. Logit regression analyses were performed with different genetic models (additive, dominant, and recessive) adjusting for confounding risk covariates, including age, sex, body mass index, total cholesterol, triglycerides, high-density lipoprotein cholesterol, low-density lipoprotein cholesterol, smoking, drinking, and family history of hypertension. The OR was $1.27(\mathrm{CI}=1.12-1.44)$ in the additive model, $1.31(\mathrm{CI}=1.09-1.59)$ in the dominant, and $1.68(\mathrm{CI}=1.28-2.19)$ in the recessive model of $\mathrm{rs} 2779249$; the OR was $1.26(\mathrm{CI}=1.06-1.50)$ in the additive model and $1.46(\mathrm{CI}=1.13-1.89)$ in the dominant model of rs2297518. The current study provides evidence that NOS2 is strongly associated with AH [26].

While genetic SNVs affect NOS2 expression, it is not known whether NOS2 gene polymorphisms affect the susceptibility to $\mathrm{AH}$ and the responses to antihypertensive therapy. Oliveira-Paula G.H. et al. (2013) studied whether NOS2 polymorphisms ((CCTTT)(n), rs2779249, andrs2297518) and haplotypes are associated with AH and responsiveness to drug therapy [27]. The authors studied 115 well-controlled hypertensive patients (HTN), 82 hypertensive patients resistant to optimized antihypertensive therapy (RHTN), and 113 normotensive healthy subjects (NT). The PHASE 2.1 software was used to estimate the haplotype frequencies in each group. Variant genotypes (GA + AA) for the rs2297518 polymorphism were more commonly found in hypertensive patients (HTN + RHTN) than in normotensives $(p=0.016 ; \mathrm{OR}=2.05)$. Authors found no associations between genotypes and responsiveness to therapy $(p>0.05)$. The S-C-A haplotype was more commonly found in hypertensive patients (HTN + RHTN) than in NT ( $p=0.014 ; \mathrm{OR}=6.07)$. Interestingly, this haplotype was more commonly found in the HTN group than in the RHTN group $(p=0.012 ; \mathrm{OR}=0.14)$. The rs2297518 polymorphism in the NOS2 gene affects the susceptibility to AH. Moreover, while the S-C-A haplotype is associated with AH, it is also associated with responsiveness to antihypertensive therapy [27].

NOS2 SNVs associative studies showed the relationship of rs2779249 and rs2297518 in haplotypes with an increased risk of primary headaches [28,29].

\subsection{NOS3 Gene}

The NOS3 gene is localized on chromosome 7q36.1 (exon count: 28) [18]. There are biased expressions of NOS3 in spleen (RPKM 28.4), placenta (RPKM 4.0), fat (RPKM 3.1), 
heart (RPKM 2.0), and nine other tissues [19]. Vascular endothelial cells produce NO, which contributes to the regulation of blood pressure and regional blood flow. The human endothelial NOS (NOS3) gene is highly polymorphic. The SNVs of the NOS3 gene are associated with $\mathrm{AH}$ development.

Yasujima M. et al. (1998) [30] examined the possible involvement of the NOS3 gene in the genetic basis for $\mathrm{AH}$. The authors identified genotypes for two SNVs of the NOS3 gene in hypertensive and normotensive populations of northern Japan. The specific genotypes for rs1799983 (Glu298Asp or $+894 \mathrm{G}>\mathrm{T}$ ) missense variant and variable numbers of tandem repeats in intron 4 (NOS3 VNTR 4b/4a) were isolated using allele-specific gene amplification and restriction fragment length polymorphisms. The 298Asp variant was significantly correlated to $\mathrm{AH}$ in these groups $(\mathrm{OR}=1.8 ; \mathrm{CI}=1.1-3.2)$. The allelic frequencies of 298Asp for Glu298 in patients with AH were significantly higher than those in normotensive subjects $(0.136$ vs. $0.083, p<0.05)$. However, there was no disequilibrium of NOS3 4b/4a between these two groups. The results suggest that rs 1799983 is a genetic susceptibility factor for AH [30]. Molecular studies have indicated that intact NOS3 Asp298 has equivalent enzymatic activity in relation to NOS3 Glu298, but undergoes selective proteolysis in native cells and tissues in such a way that the steady-state level of active NOS3 may be reduced in carriers of this allele. Carriers of NOS3 Asp298, particularly if exposed to adverse environmental influences on endothelial function, may be at increased risk of developing cerebrovascular disease, including essential $\mathrm{AH}$ and pre-eclampsia [31].

Moe K.T. et al. (2006) conducted the association analysis of NOS3 gene polymorphisms with essential AH in a Singapore population [32]. The specific genotypes for rs1799983 in exon 7, VNTR in intron 4 (NOS3 4A/B/C) and rs2070744 (-786T>C) in the promoter were isolated using allele-specific gene amplification and restriction fragment length polymorphisms to examine the association of genotype and allelic frequency in both groups. Logit regression analysis was also used to detect the association between genotypes and $\mathrm{AH}$. Five genotypes of intron 4 VNTR (AA, AB, BB, AC and BC) were observed. The intron $4 \mathrm{~B} / \mathrm{B}$ genotype was significantly associated with the AH group $(p=0.035)$, but there was no disequilibrium of rs1799983 and rs2070744 between the two groups ( $p=0.419$ and $p=0.227$ ), respectively. The overall distribution of allelic frequency differed significantly between the two groups, with the four-repeat allele (4A) of intron 4 more frequent in the normotensive group than the $\mathrm{AH}$ group $(p=0.019)$. Logit regression analysis showed that the intron $4 \mathrm{~B} / \mathrm{B}$ genotype was significantly associated with systolic blood pressure of individuals with body mass index (BMI) greater than $25 \mathrm{~kg} / \mathrm{m}^{2}(p=0.04)$. In conclusion, the NOS3 4 B/B genotype is a genetic susceptibility factor for essential AH in a Singapore population [32].

The SNV rs1799983 of the NOS3 gene has been suggested to be responsible for reduced NO synthesis and essential AH development. Nassereddine $S$ et al. (2018) evaluated the potential association of SNV rs1799983 of the NOS3 gene with AH susceptibility among a sample of Moroccan patients [33]. The results showed a positive correlation between rs1799983 NOS3 distribution and alcohol and obesity risk factors $(p=0.009$ and 0.02 , respectively). Patients with elevated cardiovascular risk (CVR) had a higher frequency of homozygous mutant genotype TT $(62.2 \%)$ and T mutant allele $(77.8 \%)$, compared to median and low CVR groups. The SNV rs1799983 of NOS3 distribution was significantly associated with a high risk of AH occurrence under the GT and TT genotypes (OR $=20.2$, $\mathrm{CI}=7.7-52.4, p<0.0001 ; \mathrm{OR}=332.5, \mathrm{CI}=98.2-1125.4, p<0.0001$; respectively), and the three genotypic transmission models (Dominant: $\mathrm{OR}=43.2, \mathrm{CI}=17.9-104.09, p<0.0001$; Recessive: $\mathrm{OR}=47.7, \mathrm{CI}=18.6-122.3, p<0.0001$; Additive: $\mathrm{OR}=14.02, \mathrm{CI}=9.6-20.45$, $p<0.0001)$. This study suggests a strong association of rs1799983 of the NOS3 gene with AH susceptibility in Morocco. Studies trying to identify contributing genes may be very useful for recognizing vulnerable individuals and classifying patients in subgroups with definite genetic and pathogenic mechanisms to achieve better prevention and therapy of $\mathrm{AH}$ [33]. In addition, a prognostic role of rs1799983 of the NOS3 gene in AH development was shown by Zhang L.P. et al. (2006) [34] and Men C. et al. (2011) [35] in China. A meta- 
analysis by Li Y.Y. (2011) [36] included the results of studies of the association between rs1799983 of the NOS3 gene and AH; electronic databases such as PubMed, Embase, Web of Science, China Biological Medicine Database (CBMD), and China National Knowledge Infrastructure (CNKI) were used. In the current meta-analysis, the T allele of SNV rs1799983 of the NOS3 gene was suggested to be related to the increased risk of AH in the Chinese population, particularly in those of Han ethnicity [36]. On the contrary, Tsujita Y. et al. (2001) [37] suggested that these SNVs (rs1799983 and rs2070744) of the NOS3 gene are unlikely to be major factors in AH susceptibility in the studied Japanese population.

An Italian study by Rossi G.T. et al. (2003) [38] showed that rs2070744 and its interaction with rs1799983 of the NOS3 gene affects endothelium-dependent vasodilation in mild-to-moderate $\mathrm{AH}$ patients and healthy normotensive Caucasian subjects.

Gamil S. et al. (2017) investigated the association between these three SNVs (rs1799983, a VNTR in intron 4, and rs2070744) in the NOS3 gene and AH development in Sudanese patients [39]. The rs2070744 polymorphism in NOS3 was found to be associated with AH in the Sudanese population as the patients group had higher frequency of the CC genotype compared to the controls $(6.6 \%$ vs. $6.1 \%, p=0.02)$. Considering the dominant inheritance model, the frequency of TC + CC genotypes in patients was significantly higher than that in the control subjects $(52.6 \%$ vs. $34.1 \%$, respectively; $p<0.01)$, with an OR $(95 \% \mathrm{CI})$ of 2.14 (1.23-3.74). In addition, the $C$ allele was more frequent in the patients than in the control group $(29.6 \%$ vs. $20 \%, p=0.03, \mathrm{OR}=1.84(1.15-2.93))$. The $\mathrm{C}$ allele of intron $4 \mathrm{VNTR}$ was reported in $>1 \%$ of the Sudanese population under study. The results of this study indicated that the rs 2070744 polymorphism in NOS3 may be a genetic susceptibility factor for essential $\mathrm{AH}$ in the Sudanese population. The $\mathrm{C}$ allele of intron 4 VNTR is not rare in the Sudanese population [39].

Salvi E. et al. (2013) [40] revealed an association between $\mathrm{AH}$ and rs3918226 in the NOS3 gene promoter (minor/major allele, T/C allele). The authors aimed at substantiating these preliminary findings by target sequencing, cell experiments, and a population study in 2722 randomly recruited Europeans (53.0\% women; mean age 40.1 years). Change in the blood pressure and incidence of $\mathrm{AH}$ in relation to rs3918226 were studied using multivariable-adjusted models. They sequenced the $140-\mathrm{kb}$ genomic area encompassing the NOS3 gene. Sequencing confirmed rs3918226, a binding site of twenty-six transcription factors, as the SNV most closely associated with AH. In T, as compared to C transfected cells, NOS3 promoter activity was from $20 \%$ to $40 \%(p<0.01)$ lower. In the population, systolic/diastolic blood pressure increased over 7.6 years (median) by $9.7 / 6.8 \mathrm{~mm} \mathrm{Hg}$ in 28 TT homozygotes and by $3.8 / 1.9 \mathrm{~mm} \mathrm{Hg}$ in $\mathrm{C}$ allele carriers $(p \leq 0.0004)$. The blood pressure rise was $5.9 \mathrm{~mm} \mathrm{Hg}$ systolic $(\mathrm{CI}=0.6-11.1 ; p=0.028)$ and $4.8 \mathrm{~mm} \mathrm{Hg}$ diastolic $(\mathrm{CI}=1.5-8.2 ; p=0.0046)$ greater in TT homozygotes, with no differences between the CT and CC genotypes ( $p \geq 0.90)$. Among 2013 participants normotensive at baseline, 692 (34.4\%) developed AH. The hazard ratio and attributable risk associated with TT homozygosity were $2.04(\mathrm{CI}=1.24-3.37 ; p=0.0054)$ and $51.0 \%$, respectively. In conclusion, rs3918226 in the NOS3 promoter tags an AH susceptibility locus, TT homozygosity being associated with lesser transcription and higher risk of $\mathrm{AH}$ [40].

The incidence of $\mathrm{AH}$ is increasing and is more common in men than in women. Up to date, the MMP3 5A/6A polymorphism has been associated with artery stiffening and elevated blood pressure, whereas results considering association of rs1799983 polymorphism of the NOS3 gene with AH are controversial. Djurić T. et al. (2005) [41] analyzed the possible association of rs1799983 and MMP3 5A/6A polymorphisms of the NOS3 gene with $\mathrm{AH}$ in a Serbian population. The study included hypertensive and normotensive subjects. There was a significantly higher $(p<0.05)$ prevalence of $5 \mathrm{~A} / 5 \mathrm{~A}$ genotype in hypertensive females compared to normotensive ones (19.30\% vs. $10.84 \%)$. This prevalence was even more pronounced in females 50 years old and above, according to its recessive effect. In young males (<40 years), the study revealed a 3.7-fold increased risk for AH associated with allele 6A $(p<0.01)$, and 8.1-fold with genotype 6A/6A $(p=0.01)$ according to the recessive model. The authors found no association of rs1799983 of NOS3 with AH. These 
results indicated that there were gender- and age-specific differences in the association of the MMP3 5A/6A polymorphism with $\mathrm{AH}$ in the Serbian population [41]. In addition, association of the rs1799983 polymorphism of the NOS3 gene with the development of pre-eclampsia in women was found [42].

Most hypertensive patients require two or more drugs to control arterial blood pressure effectively. Although NOS3 haplotypes have been associated with $\mathrm{AH}$, it is unknown whether NOS3 genotypes/haplotypes are associated with resistance to antihypertensive therapy. Sandrim V.C. et al. (2006) [43] studied the distribution of three SNVs of the NOS3 gene: SNVs in the promoter region (rs2070744, rs1799983, and VNTR in intron 4 (b/a)). Genotypes were determined for 111 normotensive controls (NT), 116 hypertensive individuals who were well controlled (HT), and 100 hypertensive individuals who were resistant to conventional antihypertensive therapy (RHT). The authors also compared the distribution of NOS3 haplotypes in the three groups of subjects. No differences were found in genotype or allele distribution among the three groups (all $p>0.05$ ). Conversely, the 'C Glu b' haplotype was more commonly found in the NT than in the HT or RHT groups (21 versus 8 and 7\%, respectively; both $p<0.00625$ ). In addition, the ' $\mathrm{C} A \mathrm{Asp} \mathrm{b}^{\prime}$ haplotype was more commonly found in the HT and RHT groups than in the NT group (22 and 20\%, respectively, versus $8 \%$; both $p<0.00625)$. The distribution of NOS3 haplotypes was not significantly different in the HT and RHT groups $(p>0.05)$. Whereas the findings suggest that (1) there is a protective effect for the 'C Glu b' haplotype against $\mathrm{AH}$, (2) the ' $\mathrm{C} A s p$ b' haplotype increases AH susceptibility, and (3) NOS3 haplotypes are not associated with resistance to antihypertensive therapy [43].

Quite a few studies have considered associations of NOS3 gene SNVs with headache. However, these works used migraine patients: Borroni B. et al. (2006) [44], Eröz R. et al. (2014) [45] showed associations with rs1799983; Gonçalves F.M. et al. (2011 [46], 2012 [22]) showed associations with rs743506; Eröz R. et al. (2014) [45], Zakerjafari M. et al. (2016) [47] showed associations with rs2070744.

\section{Discussion}

\subsection{Role of NO and NOSs in Pathogenesis and Treatment of $A H$}

$\mathrm{AH}$ is characterized by endothelial dysfunction, vasoconstriction and microvascular rarefaction. All of these mechanisms are interconnected by cause and effect relationships. Moreover, NO is involved in each of these pathogenetic mechanisms.

Thus, NO is the main mediator of endothelial dysfunction underlying the development of AH. Endothelial dysfunction is the first step in the development of atherosclerosis; it is characterized by reduced biosynthesis and decreased bioavailability of NO [11]. NO is the active radical form of both oxygen (ROS) and nitrogen (RNS). These compounds can participate in free radical chain reactions or damage organic substrates. Chain reactions are one of the main reasons why free radicals can cause damage far from where they form. Any organ or system can be exposed to oxidative or nitrosative stress. However, the most susceptible to stress are the brain (high metabolic activity and low levels of endogenous antioxidants) and the circulatory system (fluctuations in oxygen and nitric oxide levels).

In $\mathrm{AH}$, iNOS dysfunction is observed to a greater extent, since it is an isoform that catalyzes the formation of NO by endothelial cells. Li Q. et al. (2015) described the iNOS uncoupling mechanism. Tetrahydrobiopterin (BH4) is a key cofactor responsible for normal electron transfer from the reductase domain of one NOS2 monomer to the oxygenase domain of another monomer to form NO. When this cofactor is deficient, iNOS produces a superoxide anion instead of $\mathrm{NO}$ [48], which marks the induction of oxidative stress in the vessels. There are a number of studies that confirm this mechanism: with the use of an animal model $[49,50]$ and in clinical trials [51-53].

Kelm M. et al. (1996) identified three causes of NO-dependent vasospasm (impaired NO-dependent vasodilation) in patients with AH: (1) reduced NO synthesis by endothelial cells due to impaired signal transduction and/or decreased NO synthase activity, (2) accelerated NO degradation in the vessel wall, and (3) structural disorders in the vessel 
wall leading to a general decrease in the dilator capacity of resistant arteries [12]. Endothelial cells release $\mathrm{NO}$ in response to shear stress and activation of various receptors. NO stimulates guanylyl cyclase to form $3^{\prime}, 5^{\prime}$-cyclic guanosine monophosphate, which leads to vasodilation of vascular smooth muscle cells. NO has a vasodilating and antiproliferative effect on smooth muscle cells and inhibits thrombocyte aggregation and leukocyte adhesion [11].

Increased NO biosynthesis enhances angiogenesis. Conversely, angiogenesis is impaired when NO levels are reduced (e.g., in NOS2 knockout animal models). That is, conditionally, angiogenesis begins in response to hypoxia. Thus, signs of impaired angiogenesis and, as a result, microvascular rarefaction are revealed in $\mathrm{AH}$ [54]. It is important that the degree of $\mathrm{AH}$ does not affect angiogenesis, and microvascular rarefaction is also observed in normotensive people with a family history of hypertension. The genetic basis of these mechanisms has also been studied. Recent studies have confirmed that the pathway of L-arginine conversion to NO is impaired not only in people with $\mathrm{AH}$, but also in people with normotension with a history of essential AH [55].

Vascular tone is regulated by a variety of autocrine and paracrine systems. The vascular renin-angiotensin system, kallikrein-kinin system, natriuretic peptide system, endothelin, mechanosensitive ion channels, prostanoids, catecholamines, and endothelial hyperpolarizing factor are involved [12]. The impact on these systems is already actively used in $\mathrm{AH}$ therapy. Interestingly, the effects of many cardiovascular drugs used in hypertension affect the NO system. Activating NO signaling or increasing NO bioavailability are key mechanisms contributing to the positive cardiovascular effects of drugs [56]. Angiotensin-converting enzyme inhibitors, calcium channel blockers, third-generation beta blockers, and statins significantly improve endothelial function and NO bioactivity [57]. Angiogenic growth factors (vascular endothelial growth factor (VEGF) and fibroblast growth factor (FGF)) activate NOS because they require NO to function. They do this through effector molecules and their effect on the RAAS receptors. For example, bradykinin and angiotensin II induce angiogenesis [54].

Based on this, new treatment plans targeting the NO system are currently being investigated and developed; they include NO donorship and NOS stimulants [57]. In 1996, Preik M. et al. (1996) showed the effectiveness of NO donorship (glycerol trinitrate, isosorbide dinitrate and sodium nitroprusside), and also noticed that it depended not on the drug class, but on the severity of AH [58]. These data form the basis of modern research. Rajapakse N.W. et al. (2019) suggested that the decrease in NO bioavailability makes a significant contribution to the development of resistant $\mathrm{AH}$. This means that NO donorship may be the most effective treatment in this cohort of patients [59]. Today, these are pilot projects and developments, and the first clinical trials. However, they are promising and of great scientific and clinical interest.

It is assumed that drug action on the NO system, in addition to other links of therapy, is especially advisable in the case of resistant $\mathrm{AH}$ and comorbidity with other diseases (heart failure, diabetes mellitus, obesity). NO-mediated endothelial dysfunction in such patients is more pronounced. Consequently, today, when developing drugs for $\mathrm{AH}$ treatment, special attention is paid to the NO system. For example, nebivolol (a third generation $\beta$-blocker) is highly selective for $\beta 1$-adrenergic receptors and causes vasodilation through interaction with the L-arginine/NO endothelial pathway. Although nebivolol lowers blood pressure to the same extent as conventional $\beta$-blockers and other types of antihypertensive drugs, it will have a positive effect on the vascular endothelium [60]. Nebivolol releases $\mathrm{NO}$, thereby preventing the development of hypertension associated with chronic NO deficiency, and this effect appears to be dependent on inhibition of the renin-angiotensin system [15].

\subsection{Role of NO and NOSs in Pathogenesis and Treatment of TTH}

TTH is a highly prevalent disorder with a significant impact on society. Understanding the pathophysiology of TTH is paramount for development of effective treatments 
and prevention of chronic TTH [61]. Advances in basic pain and clinical research have improved our understanding of the TTH pathophysiologic mechanisms [13]. Pain perception studies such as measurement of muscle tenderness, pain detection thresholds, pain tolerance thresholds, pain response to suprathreshold stimulation, temporal summation and diffuse noxious inhibitory control have played a central role in elucidating the pathophysiology of TTH [61]. Increased excitability of the central nervous system (CNS) generated by repetitive and sustained pericranial myofascial input may be responsible for the transformation of episodic TTH into the chronic form [13]. Molecular mechanisms that underlie TTH have not yet been clarified. Studies in which TTH was induced by intravenous infusions of glyceryl trinitrate (an exogenous NO donor) and histamine (which liberates NO from vascular endothelium) suggest that NO is likely to be a responsible molecule. The release of NO from blood vessels, perivascular nerve endings or from CNS tissue is an important molecular trigger mechanism in spontaneous headache pain [14]. Sarchielli P. et al. (2001) assessed the variations in L-arginine/NO pathway activity and platelet cyclic guanosine $3^{\prime}, 5^{\prime}$-monophosphate (cGMP) levels in patients affected by chronic TTH. A reduction in platelet aggregation response was found. The reduction in platelet aggregation was coupled with increased NO and cGMP production. A significant increase in cytosolic $\mathrm{Ca}(2+)$ concentration was also detected compared to control individuals. This was accompanied by a reduced platelet content and collagen-induced secretion of serotonin and increased content of NO in patients with TTH. The above findings were more pronounced in patients with analgesic abuse. It can be hypothesized that the increased NOS activity shown in platelets of TTH patients reflects an analogous central up-regulation of NOS activity in the spinal horn/trigeminal nucleus and supraspinal structures; these structures are involved in the modulation of nociceptive input from myofascial cranial structures contributing to central sensitization. The increase in NOS activity seems to be associated with a hyposerotonergic status, particularly in patients with analgesic abuse. This can contribute to central sensitization in patients with TTH. The increase in platelet glutamate content in the same patients suggests the implication of the above excitatory amino acid in spinal and supraspinal structures involved in head pain induction and maintenance [62].

Tenderness of pericranial myofascial tissues and number of myofascial trigger points are considerably increased in patients with TTH. Mechanisms responsible for the increased myofascial pain sensitivity have been studied extensively. Peripheral activation or sensitization of myofascial nociceptors could be one of the causes for increased pain sensitivity, but firm evidence for a peripheral abnormality is still lacking. Peripheral mechanisms are most likely of major importance in episodic TTH [63]. Sensitization of pain pathways in CNS due to prolonged nociceptive stimuli from pericranial myofascial tissues seems to be responsible for TTH chronification. Neck muscle nociception mediated by NO may play a role in TTH pathophysiology [16]. The role of NO in the antinociceptive effect of indomethacin was assessed in the pain-induced functional impairment model in the rat (PIFIR model); the antinociceptive effect of indomethacin involves, at least in part, the NO-cyclic GMP pathway at the peripheral level [64]. Furthermore, the role of NO in the antinoceptive effect of other drugs used for TTH treatment (diclofenac [65]; ketorolac [66]; nimesulide [67]; celecoxib [68]; rofecoxib [69]; gabapentin [70]; melatonin [71]) has been shown.

Chronic TTH may be caused by prolonged painful input from pericranial myofacial tissues, such as tender points, which results in central sensitization (increased excitability of neurons in the CNS). Animal studies have shown that sensitization of pain pathways may be caused by or associated with activation of nNOS and generation of NO. Furthermore, it has been shown that NOS inhibitors reduce central sensitization in animal models of persistent pain [72].

nNOS is involved in the induction but not the maintenance of nerve growth factor (NGF) caused by facilitation of nociception in the brainstem. The results from an experimental animal model may support the idea of nNOS and eNOS as potential targets for pharmacological treatment of TTH [16]. Infusion of $\alpha, \beta$-methylene ATP $(\alpha, \beta$-meATP) into 
murine neck muscle facilitates brainstem nociception. Unspecific NOSs inhibition prevents and reverses this sensitization. It is unclear whether nNOS, iNOS or eNOS isoenzymes are involved in this $\alpha, \beta$-meATP effect. Ristic D. et al. (2010) provided evidence that nNOS plays a major role in induction and eNOS in maintenance of facilitation in neck muscle nociception. Divergent roles of NOS isoenzymes may promote research on target-specific treatments for headache and neck muscle pain [17].

The role of nNOS and iNOS in central sensitization induced by an intradermal capsaicin injection was investigated by Wu J. et al. (2001) [73]. Obtained results by Budziñski M. et al. (2000) suggest that NO derived from iNOS plays an inhibitory role in carrageenanproduced hyperalgesia in rat [74].

The analgesic effect of the NOS inhibitor L-N(G) methyl arginine hydrochloride was investigated. This drug significantly reduced headache and myofascial factors in patients with chronic TTH. These studies show that NO plays a crucial role in the pathophysiology of TTH. The analgesic effect of NOS inhibition in patients with chronic TTH is probably due to a reduction in central sensitization at the level of the spinal dorsal horn, trigeminal nucleus or both. Furthermore, NOS inhibition may become a novel principle in the future treatment of chronic TTH [72].

\subsection{Role of SNVs of NOSs Genes in the AH and TTH Phenotype and Comorbidites}

All three isoforms of the protein (nNOS, iNOS, eNOS) and its genes (NOS1, NOS2, NOS3) described above play key roles in the pathogenesis of both AH and TTH. They also negatively influence the leading environmental trigger of these nosologies: stress (Figure 2) and related neuropsychological disorders (anxiety and depression) [75].

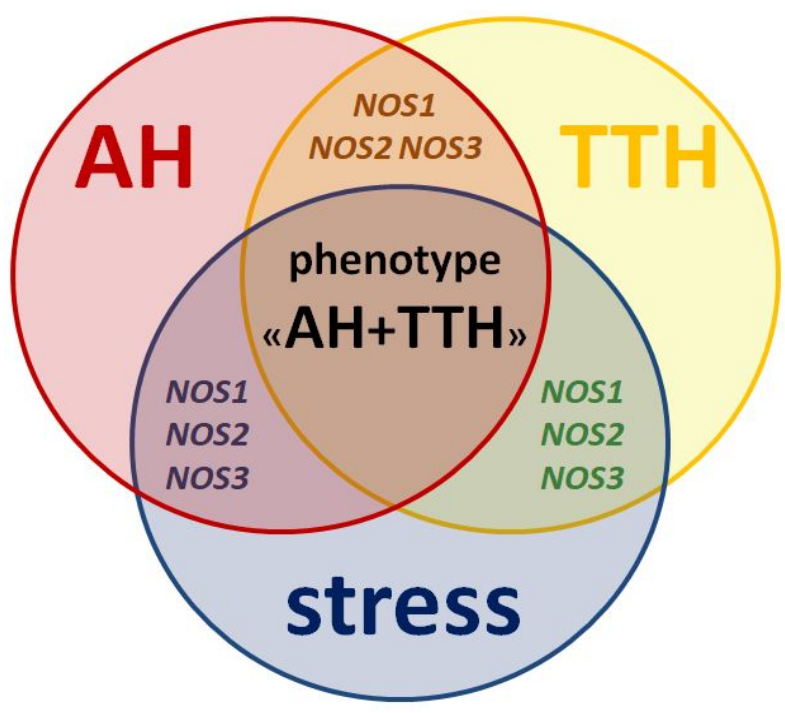

Figure 2. Similarities in pathogenesis and unresolved issues of the role of NOS1, NOS2, NOS3 genes as genetic predictors of the $\mathrm{AH}+\mathrm{TTH}$ phenotype.

However, the prognostic role of NOS1, NOS2, NOS3 genes in the development of the common $\mathrm{AH}+\mathrm{TTH}$ phenotype has not been studied in comparison with the second most common phenotype ( $\mathrm{AH}+$ migraine). Our analysis testifies to the importance of planning and conducting associative genetic research in the role of NOS1, NOS2, NOS3 genes as genetic predictors of the AH + TTH phenotype (Figure 3) in various racial and ethnic groups.

This is important from a scientific and clinical point of view, because a new class of drugs that inhibit NOSs has been proposed in recent years, both for the treatment of AH and TTH. A new strategy for predicting and disease-modifying therapy of the common $\mathrm{AH}+\mathrm{TTH}$ phenotype can increase the effectiveness and safety of treatment, 
improve patient's quality of life, and reduce the risk of life-threatening cardiovascular complications.

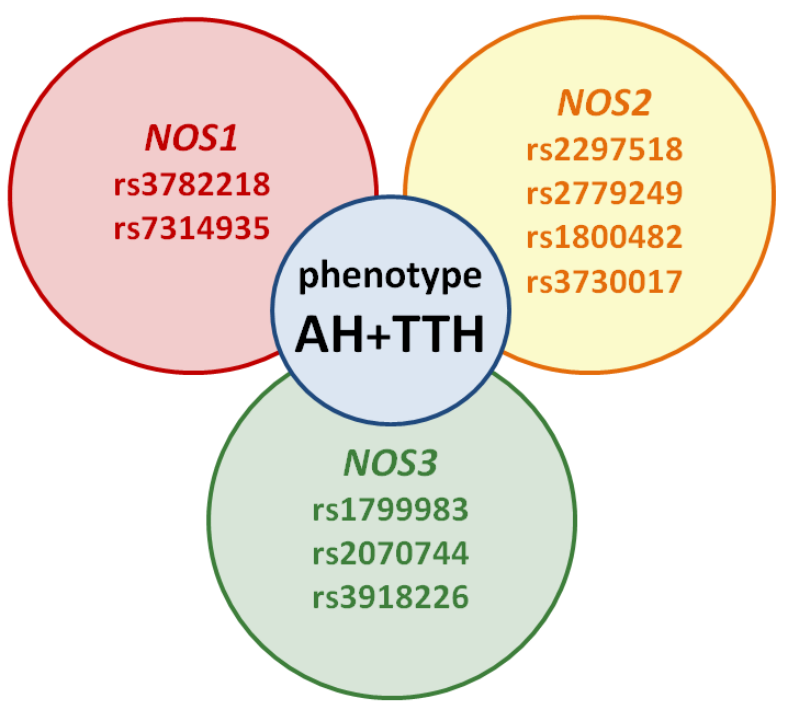

Figure 3. Potential SNVs of NOS1, NOS2, NOS3 genes predisposed to the AH + TTH phenotype.

\section{Materials and Methods}

We searched for full-text English publications from the past 15 years in the PubMed, Springer, Scopus, Web of Science, Clinicalkeys, and Google Scholar databases using keywords and combined word searches (nitric oxide; nitric oxide synthase; single nucleotide variants; single nucleotide polymorphisms; genes; NOS1; NOS2; NOS3; arterial hypertension; tension-type headache). We considered studies published from 2005 to 2020 and identified 32 publications devoted to the search for genetic predictors of the NO-synthase system in the development of $\mathrm{AH}$ and headache. Based on search criteria, only 24 of these publications were included in this review. In our review, we summed up SNVs of NOS1, NOS2, NOS3 genes involved in the development of essential AH and headache. In addition, three earlier publications were included (1998, 2001 and 2003), to compare more racial and ethnic groups. The results of studies we have discussed in this review are contradictory. This might be due to different designs of the studies, small sample sizes in some of them, as well as different social and geographical characteristics.

\section{Conclusions}

$\mathrm{NO}$ has a free electron (NO), but despite being a free radical, it is not toxic as such. By reacting with superoxide, however, it forms peroxynitrite, which is a highly reactive free radical that exerts noxious effects on tissues. This mechanism is used in defense against infections, when iNOS is activated and produces NO in high concentrations. It is uncertain whether free radical formation plays a role at the lower concentrations of $\mathrm{NO}$ seen in endothelium and neurons [76].

The results of studies we have discussed in this review are contradictory, which might be due to different designs of the studies, small sample sizes in some of them, as well as different social and geographical characteristics. However, the contribution of genetic and environmental factors has been understudied, which makes this issue interesting for researchers, as understanding these mechanisms can support a search for new approaches to pathogenetic and disease-modifying treatment of the AH and TTH phenotype. New drugs against $\mathrm{AH}$ and TTH can be based on inhibition of nitric oxide (NO) production, blockade of steps in the NO-cGMP pathway, or NO scavenging [76]. 
Author Contributions: Conceptualization, N.A.S.; investigation, N.A.S. and P.V.M.; writing—original draft preparation, N.A.S. and P.V.M.; writing-review and editing, E.A.P.; supervision, M.M.P., P.A.S. and R.F.N.; project administration, N.A.S. and R.F.N.; funding acquisition, M.M.P. and P.A.S. All authors have read and agreed to the published version of the manuscript.

Funding: This research received no external funding.

Acknowledgments: This work was carried out on the basis of a shared Core Facilities Molecular and Cell Technologies, V.F. Voino-Yasenetsky Krasnoyarsk State Medical University, Krasnoyarsk, Russian Federation.

Conflicts of Interest: The authors declare no conflict of interest.

\section{References}

1. Rapsomaniki, E.; Timmis, A.; George, J.; Pujades-Rodriguez, M.; Shah, A.D.; Denaxas, S.; White, I.R.; Caulfield, M.J.; Deanfield, J.E.; Smeeth, L.; et al. Blood pressure and incidence of twelve cardiovascular diseases: Lifetime risks, healthy life-years lost, and age-specific associations in 1.25 million people. Lancet 2014, 383, 1899-1911. [CrossRef]

2. Chowdhury, D. Tension type headache. Ann. Indian Acad. Neurol. 2012, 15 (Suppl. S1), S83-S88. [CrossRef]

3. Petrova, M.M.; Moskaleva, P.V.; Shnayder, N.A.; Nasyrova, R.F. Comorbidity of arterial hypertension and tension-type headache (In Russ.). Kardiologiia 2020, 60, 132-140. [CrossRef]

4. Saccò, M.; Meschi, M.; Regolisti, G.; Detrenis, S.; Bianchi, L.; Bertorelli, M.; Pioli, S.; Magnano, A.; Spagnoli, F.; Giuri, P.G.; et al. The relationship between blood pressure and pain. J. Clin. Hypertens. 2013, 15, 600-605. [CrossRef]

5. Olesen, J. The role of nitric oxide (NO) in migraine, tension-type headache and cluster headache. Pharmacol. Ther. 2008, 120, 157-171. [CrossRef] [PubMed]

6. Ashina, M.; Bendtsen, L.; Jensen, R.; Olesen, J. Nitric oxide-induced headache in patients with chronic tension-type headache. Brain 2000, 123 Pt 9, 1830-1837. [CrossRef]

7. Mattila, J.T.; Thomas, A.C. Nitric oxide synthase: Non-canonical expression patterns. Front. Immunol. 2014, 5, 478. [CrossRef]

8. Hua, Y. Neuronal nitric oxide synthase in hypertension-An update. Clin. Hypertens. 2016, 22, 20. [CrossRef]

9. Förstermann, U.; Sessa, W.C. Nitric oxide synthases: Regulation and function. Eur. Heart J. 2012, 33, 829-837. [CrossRef]

10. Förstermann, U.; Münzel, T. Endothelial nitric oxide synthase in vascular disease: From marvel to menace. Circulation 2006, 113, 1708-1714. [CrossRef]

11. Hermann, M.; Flammer, A.; Lüscher, T.F. Nitric oxide in hypertension. J. Clin. Hypertens. 2006, 8 (Suppl. S4), 17-29. [CrossRef] [PubMed]

12. Kelm, M.; Preik, M.; Hafner, D.J.; Strauer, B.E. Evidence for a multifactorial process involved in the impaired flow response to nitric oxide in hypertensive patients with endothelial dysfunction. Hypertension 1996, 27 Pt 1, 346-353. [CrossRef]

13. Ashina, S.; Bendtsen, L.; Ashina, M. Pathophysiology of tension-type headache. Curr. Pain Headache Rep. 2005, 9, 415-422. [CrossRef]

14. Thomsen, L.L.; Olesen, J. Nitric oxide in primary headaches. Curr. Opin. Neurol. 2001, 14, 315-321. [CrossRef] [PubMed]

15. Fortepiani, L.A.; Ortíz, M.C.; Atucha, N.M.; García-Estañ, J. Nebivolol ameliorates nitric oxide deficient hypertension. Sci. World J. 2002, 2, 1676-1684. [CrossRef]

16. Isaak, A.; Ellrich, J. Neuronal nitric oxide synthase is involved in the induction of nerve growth factor-induced neck muscle nociception. Headache 2011, 51, 734-743. [CrossRef] [PubMed]

17. Ristic, D.; Spangenberg, P.; Ellrich, J. Inhibition of nNOS prevents and inhibition of iNOS reverses $\alpha, \beta$-meATP-induced facilitation of neck muscle nociception in mice. Eur. J. Pharmacol. 2010, 647, 55-61. [CrossRef] [PubMed]

18. NCBI. Available online: https:/ / www.ncbi.nlm.nih.gov (accessed on 15 January 2021).

19. Fagerberg, L.; Hallström, B.M.; Oksvold, P.; Kampf, C.; Djurinovic, D.; Odeberg, J.; Habuka, M.; Tahmasebpoor, S.; Danielsson, A.; Edlund, K.; et al. Analysis of the human tissue-specific expression by genome-wide integration of transcriptomics and antibodybased proteomics. Mol. Cell Proteom. 2014, 13, 397-406. [CrossRef]

20. Levinsson, A.; Olin, A.C.; Björck, L.; Rosengren, A.; Nyberg, F. Nitric oxide synthase (NOS) single nucleotide polymorphisms are associated with coronary heart disease and hypertension in the INTERGENE study. Nitric. Oxide. 2014, 39, 1-7. [CrossRef] [PubMed]

21. Alaşehirli, B.; Akçalı, A.; Demiryürek, A.T.; Özel, A.; Erdal, M.E.; Neyal, M. Lack of association between the C276T polymorphism of the neuronal nitric oxide synthase gene and migraine. Int. J. Neurosci. 2013, 123, 50-54. [CrossRef]

22. García-Martín, E.; Martínez, C.; Serrador, M.; Alonso-Navarro, H.; Navacerrada, F.; García-Albea, E.; Agúndez, J.A.; JiménezJiménez, F.J. Neuronal Nitric Oxide Synthase (nNOS, NOS1) rs693534 and rs7977109 Variants and Risk for Migraine. Headache 2015, 55, 1209-1217. [CrossRef]

23. Fu, L.; Zhao, Y.; Lu, J.; Shi, J.; Li, C.; Liu, H.; Li, Y. Functional single nucleotide polymorphism-1026C/A of inducible nitric oxide synthase gene with increased YY1-binding affinity is associated with hypertension in a Chinese Han population. J. Hypertens. 2009, 27, 991-1000. [CrossRef] [PubMed] 
24. Topchieva, L.V.; Balan, O.V.; Korneeva, V.A.; Malysheva, I.E. The role of Inducible $\mathrm{NOS}_{2}$ gene polymorphism in the development of essential arterial hypertension. Bull. Exp. Biol. Med. 2019, 168, 79-83. [CrossRef]

25. Nikkari, S.T.; Määttä, K.M.; Kunnas, T.A. Functional Inducible Nitric Oxide Synthase Gene Variants Associate with Hypertension: A Case-Control Study in a Finnish Population-The TAMRISK Study. Medicine 2015, 94, e1958. [CrossRef] [PubMed]

26. Zhai, Z.; Wang, Z.; Wang, L.; Chen, S.; Ren, H.; Wang, D. Relationship between inducible NOS single-nucleotide polymorphisms and hypertension in Han Chinese. Zusammenhang zwischen iNOS-Einzelnukleotidpolymorphismen und Hypertonie bei Han-Chinesen. Herz 2018, 43, 461-465. [CrossRef] [PubMed]

27. Oliveira-Paula, G.H.; Lacchini, R.; Coeli-Lacchini, F.B.; Junior, H.M.; Tanus-Santos, J.E. Inducible nitric oxide synthase haplotype associated with hypertension and responsiveness to antihypertensive drug therapy. Gene 2013, 515, 391-395. [CrossRef]

28. de Mansur, T.O.S.; Gonçalves, F.M.; Martins-Oliveira, A.; Speciali, J.G.; Dach, F.; Lacchini, R.; Tanus-Santos, J.E. Inducible nitric oxide synthase haplotype associated with migraine and aura. Mol. Cell Biochem. 2012, 364, 303-308. [CrossRef]

29. Gonçalves, F.M.; Luizon, M.R.; Speciali, J.G.; Martins-Oliveira, A.; Dach, F.; Tanus-Santos, J.E. Interaction among nitric oxide (NO)-related genes in migraine susceptibility. Mol. Cell Biochem. 2012, 370, 183-189. [CrossRef] [PubMed]

30. Yasujima, M.; Tsutaya, S.; Shoji, M. Endothelial nitric oxide synthase gene polymorphism and hypertension (In Japanese). Rinsho Byori 1998, 46, 1199-1204.

31. Hingorani, A.D. Endothelial nitric oxide synthase polymorphisms and hypertension. Curr. Hypertens. Rep. 2003, 5, 19-25. [CrossRef]

32. Moe, K.T.; Lim, S.T.; Wong, P.; Chua, T.; DeSilva, D.A.; Koh, T.H.; Wong, M.C.; Chin-Dusting, J. Association analysis of endothelial nitric oxide synthase gene polymorphism with primary hypertension in a Singapore population. J. Hum. Hypertens. 2006, 20, 956-963. [CrossRef]

33. Nassereddine, S.; Idrissi, H.H.; Habbal, R.; Abouelfath, R.; Korch, F.; Haraka, M.; Karkar, A.; Nadifi, S. The polymorphism G894T of endothelial nitric oxide synthase (eNOS) gene is associated with susceptibility to essential hypertension (EH) in Morocco. BMC Med. Genet. 2018, 19, 127. [CrossRef]

34. Zhang, L.P.; Wang, S.Z.; Zhao, X.X.; Lian, B.; Wang, X.F.; Lin, R.Y.; Lu, D.R.; Jin, L. Association between endothelial nitric oxide synthase gene (G894T) polymorphism and essential hypertension in Uygur populations (In Chinese). Zhonghua Xin Xue Guan Bing Za Zhi 2006, 34, 403-406.

35. Men, C.; Tang, K.; Lin, G.; Li, J.; Zhan, Y. ENOS-G894T polymorphism is a risk factor for essential hypertension in China. Indian J. Biochem. Biophys. 2011, 48, 154-157.

36. Li, Y.Y. Endothelial nitric oxide synthase G894T gene polymorphism and essential hypertension in the Chinese population: A meta-analysis involving 11,248 subjects. Intern. Med. 2011, 50, 2099-2106. [CrossRef]

37. Tsujita, Y.; Baba, S.; Yamauchi, R.; Mannami, T.; Kinoshita, M.; Yamamoto, R.; Katsuya, T.; Higaki, J.; Ogihara, T.; Ogata, J.; et al. Association analyses between genetic polymorphisms of endothelial nitric oxide synthase gene and hypertension in Japanese: The Suita Study. J. Hypertens. 2001, 19, 1941-1948. [CrossRef] [PubMed]

38. Rossi, G.P.; Taddei, S.; Virdis, A.; Cavallin, M.; Ghiadoni, L.; Favilla, S.; Versari, D.; Sudano, I.; Pessina, A.C.; Salvetti, A. The T-786C and Glu298Asp polymorphisms of the endothelial nitric oxide gene affect the forearm blood flow responses of Caucasian hypertensive patients. J. Am. Coll. Cardiol. 2003, 41, 938-945. [CrossRef]

39. Gamil, S.; Erdmann, J.; Abdalrahman, I.B.; Mohamed, A.O. Association of $\mathrm{NOS}_{3}$ gene polymorphisms with essential hypertension in Sudanese patients: A case control study. BMC Med. Genet. 2017, 18, 128. [CrossRef]

40. Salvi, E.; Kuznetsova, T.; Thijs, L.; Lupoli, S.; Stolarz-Skrzypek, K.; D'Avila, F.; Tikhonoff, V.; de Astis, S.; Barcella, M.; Seidlerová, J.; et al. Target sequencing, cell experiments, and a population study establish endothelial nitric oxide synthase (eNOS) gene as hypertension susceptibility gene. Hypertension 2013, 62, 844-852. [CrossRef] [PubMed]

41. Djurić, T.; Zivković, M.; Stanković, A.; Mecanin, S.; Alavantić, D. Endothelial NOS G894 T and MMP-3 5A/6A gene polymorphisms and hypertension in Serbian population. J. Clin. Lab. Anal. 2005, 19, 241-246. [CrossRef] [PubMed]

42. Sakar, M.N.; Atay, A.E.; Demir, S.; Bakir, V.L.; Demir, B.; Balsak, D.; Akay, E.; Ulusoy, A.I.; Verit, F.F. Association of endothelial nitric oxide synthase gene G894T polymorphism and serum nitric oxide levels in patients with preeclampsia and gestational hypertension. J. Matern. Fetal Neonatal Med. 2015, 28, 1907-1911. [CrossRef]

43. Sandrim, V.C.; Yugar-Toledo, J.C.; Desta, Z.; Flockhart, D.A.; Moreno, H., Jr.; Tanus-Santos, J.E. Endothelial nitric oxide synthase haplotypes are related to blood pressure elevation, but not to resistance to antihypertensive drug therapy. J. Hypertens. 2006, 24, 2393-2397. [CrossRef]

44. Borroni, B.; Rao, R.; Liberini, P.; Venturelli, E.; Cossandi, M.; Archetti, S.; Caimi, L.; Padovani, A. Endothelial nitric oxide synthase (Glu298Asp) polymorphism is an independent risk factor for migraine with aura. Headache 2006, 46, 1575-1579. [CrossRef]

45. Eröz, R.; Bahadir, A.; Dikici, S.; Tasdemir, S. Association of endothelial nitric oxide synthase gene polymorphisms (894G/T, -786T/C, G10T) and clinical findings in patients with migraine. Neuromol. Med. 2014, 16, 587-593. [CrossRef] [PubMed]

46. Gonçalves, F.M.; Martins-Oliveira, A.; Speciali, J.G.; Luizon, M.R.; Izidoro-Toledo, T.C.; Silva, P.S.; Dach, F.; Tanus-Santos, J.E. Endothelial nitric oxide synthase haplotypes associated with aura in patients with migraine. DNA Cell Biol. 2011, 30, 363-369. [CrossRef]

47. Zakerjafari, M.; Dehkordi, F.F.; Yaghoubi, H. Evaluation of NOS 3 T-C 786 Gene Polymorphism in Iranian Patients affected by Migraine and Normal individuals. Adv. Biores. 2016, 7, 16-19. [CrossRef] 
48. Li, Q.; Youn, J.Y.; Cai, H. Mechanisms and consequences of endothelial nitric oxide synthase dysfunction in hypertension. J. Hypertens. 2015, 33, 1128-1136. [CrossRef] [PubMed]

49. Shinozaki, K.; Nishio, Y.; Okamura, T.; Yoshida, Y.; Maegawa, H.; Kojima, H.; Masada, M.; Toda, N.; Kikkawa, R.; Kashiwagi, A. Oral administration of tetrahydrobiopterin prevents endothelial dysfunction and vascular oxidative stress in the aortas of insulin-resistant rats. Circ. Res. 2000, 87, 566-573. [CrossRef]

50. Podjarny, E.; Hasdan, G.; Bernheim, J.; Rashid, G.; Green, J.; Korzets, Z.; Bernheim, J. Effect of chronic tetrahydrobiopterin supplementation on blood pressure and proteinuria in 5/6 nephrectomized rats. Nephrol. Dial. Transplant. 2004, 19, $2223-2227$. [CrossRef]

51. Ihlemann, N.; Rask-Madsen, C.; Perner, A.; Dominguez, H.; Hermann, T.; Køber, L.; Torp-Pedersen, C. Tetrahydrobiopterin restores endothelial dysfunction induced by an oral glucose challenge in healthy subjects. Am. J. Physiol. Heart Circ. Physiol. 2003, 285, H875-H882. [CrossRef]

52. Maier, W.; Cosentino, F.; Lütolf, R.B.; Fleisch, M.; Seiler, C.; Hess, O.M.; Meier, B.; Lüscher, T.F. Tetrahydrobiopterin improves endothelial function in patients with coronary artery disease. J. Cardiovasc. Pharmacol. 2000, 35, 173-178. [CrossRef] [PubMed]

53. Hambrecht, R.; Hilbrich, L.; Erbs, S.; Gielen, S.; Fiehn, E.; Schoene, N.; Schuler, G. Correction of endothelial dysfunction in chronic heart failure: Additional effects of exercise training and oral L-arginine supplementation. J. Am. Coll. Cardiol. 2000, 35, 706-713. [CrossRef]

54. Kiefer, F.N.; Neysari, S.; Humar, R.; Li, W.; Munk, V.C.; Battegay, E.J. Hypertension and angiogenesis. Curr. Pharm. Des. 2003, 9 , 1733-1744. [CrossRef]

55. Schlaich, M.P.; Parnell, M.M.; Ahlers, B.A.; Finch, S.; Marshall, T.; Zhang, W.Z.; Kaye, D.M. Impaired L-arginine transport and endothelial function in hypertensive and genetically predisposed normotensive subjects. Circulation 2004, 110, 3680-3686. [CrossRef]

56. Pinheiro, L.C.; Tanus-Santos, J.E.; Castro, M.M. The potential of stimulating nitric oxide formation in the treatment of hypertension. Expert Opin. Ther. Targets 2017, 21, 543-556. [CrossRef] [PubMed]

57. Giles, T.D. Aspects of nitric oxide in health and disease: A focus on hypertension and cardiovascular disease. J. Clin. Hypertens. 2006, 8 (Suppl. S4), 2-16. [CrossRef]

58. Preik, M.; Kelm, M.; Feelisch, M.; Strauer, B.E. Impaired effectiveness of nitric oxide-donors in resistance arteries of patients with arterial hypertension. J. Hypertens. 1996, 14, 903-908. [CrossRef]

59. Rajapakse, N.W.; Giam, B.; Kuruppu, S.; Head, G.A.; Kaye, D.M. Impaired L-arginine-nitric oxide pathway contributes to the pathogenesis of resistant hypertension. Clin. Sci. 2019, 133, 2061-2067. [CrossRef] [PubMed]

60. Toblli, J.E.; DiGennaro, F.; Giani, J.F.; Dominici, F.P. Nebivolol: Impact on cardiac and endothelial function and clinical utility. Vasc. Health Risk Manag. 2012, 8, 151-160. [CrossRef] [PubMed]

61. Bezov, D.; Ashina, S.; Jensen, R.; Bendtsen, L. Pain perception studies in tension-type headache. Headache 2011, 51, $262-271$. [CrossRef]

62. Sarchielli, P.; Alberti, A.; Floridi, A.; Gallai, V. L-Arginine/nitric oxide pathway in chronic tension-type headache: Relation with serotonin content and secretion and glutamate content. J. Neurol. Sci. 2002, 198, 9-15. [CrossRef]

63. Bendtsen, L.; Fernández-de-la-Peñas, C. The role of muscles in tension-type headache. Curr. Pain Headache Rep. 2011, 15, 451-458. [CrossRef]

64. Ventura-Martínez, R.; Déciga-Campos, M.; Díaz-Reval, M.I.; González-Trujano, M.E.; López-Muñoz, F.J. Peripheral involvement of the nitric oxide-cGMP pathway in the indomethacin-induced antinociception in rat. Eur. J. Pharmacol. 2004, 503, 43-48. [CrossRef] [PubMed]

65. Ortiz, M.I.; Torres-López, J.E.; Castañeda-Hernández, G.; Rosas, R.; Vidal-Cantú, G.C.; Granados-Soto, V. Role of the nitric oxide-cyclic GMP- $\mathrm{K}^{+}$channel pathway in the antinociception induced by atrial natriuretic peptide (ANP) and diclofenac. Proc. West Pharmacol. Soc. 2002, 45, 174-177. [PubMed]

66. Lázaro-Ibáñez, G.G.; Torres-López, J.E.; Granados-Soto, V. Participation of the nitric oxide-cyclic GMP-ATP-sensitive K ${ }^{+}$channel pathway in the antinociceptive action of ketorolac. Eur. J. Pharmacol. 2001, 426, 39-44. [CrossRef]

67. Islas-Cadena, M.; Aguirre-Bañuelos, P.; Granados-Soto, V. Evidence for the participation of the nitric oxide-cyclic GMP pathway in the antinociceptive effect of nimesulide. J. Pharmacol. Toxicol. Methods 1999, 42, 87-92. [CrossRef]

68. Klein, T.; Eltze, M.; Grebe, T.; Hatzelmann, A.; Kömhoff, M. Celecoxib dilates guinea-pig coronaries and rat aortic rings and amplifies NO/cGMP signaling by $\mathrm{PDE}_{5}$ inhibition. Cardiovasc. Res. 2007, 75, 390-397. [CrossRef]

69. Déciga-Campos, M.; López-Muñoz, F.J. Participation of the NO-cyclic GMP pathway in rofecoxib-induced antinociception. Proc. West Pharmacol. Soc. 2003, 46, 165-167.

70. Mixcoatl-Zecuatl, T.; Flores-Murrieta, F.J.; Granados-Soto, V. The nitric oxide-cyclic GMP-protein kinase G-K ${ }^{+}$channel pathway participates in the antiallodynic effect of spinal gabapentin. Eur. J. Pharmacol. 2006, 531, 87-95. [CrossRef] [PubMed]

71. Hernández-Pacheco, A.; Araiza-Saldaña, C.I.; Granados-Soto, V.; Mixcoatl-Zecuatl, T. Possible participation of the nitric oxidecyclic GMP-protein kinase G-K ${ }^{+}$channels pathway in the peripheral antinociception of melatonin. Eur. J. Pharmacol. 2008, 596, 70-76. [CrossRef]

72. Ashina, M. Nitric oxide synthase inhibitors for the treatment of chronic tension-type headache. Expert Opin. Pharmacother. 2002, 3, 395-399. [CrossRef] 
73. Wu, J.; Fang, L.; Lin, Q.; Willis, W.D. Nitric oxide synthase in spinal cord central sensitization following intradermal injection of capsaicin. Pain 2001, 94, 47-58. [CrossRef]

74. Budziñski, M.; Misterek, K.; Gumulka, W.; Dorociak, A. Inhibition of inducible nitric oxide synthase in persistent pain. Life Sci. 2000, 66, 301-305. [CrossRef]

75. Nasyrova, R.F.; Moskaleva, P.V.; Vaiman, E.E.; Shnayder, N.A.; Blatt, N.L.; Rizvanov, A.A. Genetic Factors of Nitric Oxide's System in Psychoneurologic Disorders. Int. J. Mol. Sci. 2020, 21, 1604. [CrossRef] [PubMed]

76. Olesen, J. Nitric oxide-related drug targets in headache. Indeed, selective n-NOS and i-NOS inhibitors are already in early clinical development. Neurotherapeutics 2010, 7, 183-190. [CrossRef] 